\title{
BCCiN4
}

\section{COMPRESSIVE STRESS-STRAIN BEHAVIOUR OF R-PET FIBRE REINFORCED MORTARS}

\author{
Matheus S. V. Fernandes ${ }^{(1)}, \underline{\text { Margareth S. Magalhães }}{ }^{(1)}$ and Rodrigo B. Burgos ${ }^{(1)}$ \\ (1) Postgraduate Program in Civil Engineering, Rio de Janeiro State University (UERJ), Rio \\ de Janeiro, RJ, Brazil.
}

https://doi.org/10.21452/bccm4.2018.02.33

\begin{abstract}
This paper deals with an experimental and analytical study on the influence of recycled polyethylene terephthalate (R-PET) fibres as reinforcement of mortars. The mixtures were produced using Portland cement, fly ash, silica sand, superplasticizer and different amounts of R-PET fibres (0\%, $1.0 \%$ and $2.0 \%$ ). Dry density, total porosity and compressive tests were carried out. The results indicated that the incorporation of R-PET fibres significantly improves the post-cracking behaviour of mortars with a major improvement in mortar toughness. However, the addition of R-PET had no beneficial effect on the compressive strength and elastic modulus of the composite mixtures with $1 \%$ and $2 \%$. A reduction of strength (up to 54\%) and elastic modulus (up to 28\%) was observed for composite mixtures due to increased porosity caused by fibre addition. Analytical models found in the literature for stress-strain behaviour were used along with curve fitting algorithms.
\end{abstract}

Keywords: Cement based composites, R-PET fibres, stress-strain behaviour.

\section{INTRODUCTION}

Polyethylene terephthalate (PET) is one of the most important and extensively used plastics in the world, especially for manufacturing beverage containers. In 2016, the worldwide annual consumption represented 480 billion PET bottles. However, most PET used as beverage bottles are thrown away after a single usage and disposed bottles are managed by landfill or incineration, which is causing serious environmental problems. Plastic materials are non-biodegradable in nature and burning is not a solution to consume such waste because this process releases dangerous chemical gases into the air. According to ABIPET [1], in 2015 only $51 \%$ of terephthalate bottles were recycled in Brazil.

Considerable research has been undertaken on the potential use of recycled PET (R-PET) in replacing natural aggregates of plain concrete [2,3], reinforced concrete beams [4] or as reinforcement of cementitious matrices $[5,6,7,8,9,10]$, since fibres can overcome some disadvantages of concrete, such as low energy absorption and low ductility [11]. 
In general, addition of R-PET fibre in cement-based materials improves the splitting tensile strength [12], flexural strength and ductility $[5,13]$ of plain concrete or mortar. R-PET fibres also provide excellent impact resistance [14] and demonstrate excellent characteristics in suppressing early-age crack generation [6] of cement-based materials.

Ochi et al. [5] and Kim et al. [6] investigated the bond behaviour of R-PET fibres with a concrete matrix, discussing the effects of the fibre surface characteristics. Embossed fibres provided the highest bond strength, followed by crimped and straight ones.

Regarding the influence of R-PET fibres on the compressive strength of R-PET composites, contradictory results have been found in the literature. Ochi et al. [5] reported a moderate increase of the compressive strength (from 6\% to 13\%) for fibre volume fractions up to 1\%; however, for higher fibre content, this increase diminished or even turned into a decrease. On the other hand, Kim et al. [13] reported a moderate decrease of up to $9 \%$ for fibre contents of $0.5-1 \%$ and Borg et al [15] reported that the addition of R-PET fibres leads to a reduction between $0.5 \%$ and $8.5 \%$ in compressive strength when compared to the reference mixture. All studies agree that R-PET composites feature a lower elastic modulus than the plain matrix, decreasing with the increase in fibre content.

In this work, experimental results regarding compressive properties of an eco-friendly mortar reinforced with R-PET fibre are presented. The main objective of this study is, therefore, to investigate the influence of the addition of R-PET fibre on the compressive stress-strain behaviour of mortar. Compressive tests are used to analyse and characterize composites with different fibre volume contents $(1.0 \%$ and $2.0 \%)$. Several analytical models found in the literature were tested against experimental data.

\section{EXPERIMENTAL PROGRAM}

\section{2.1 Raw materials and composite manufacturing}

The mixtures were produced using CPII F-32 Portland cement (6\% calcareous filler), with $32 \mathrm{MPa}$ compressive strength at 28 days and density of $3.08 \mathrm{~g} / \mathrm{cm}^{3}$; fly ash with density of $2.35 \mathrm{~g} / \mathrm{cm}^{3}$; silica sand with maximum diameter of $212 \mu \mathrm{m}$ and density of $2.60 \mathrm{~g} / \mathrm{cm}^{3}$; a superplasticizer, Glenium 51 (manufactured by MBT Brazil) based on modified polycarboxylic ether with $32.5 \%$ solid content and density of $1.20 \mathrm{~g} / \mathrm{cm}^{3}$ and R-PET fibre.

The R-PET fibre used in this study is produced by M\&G Fibras Brazil LTDA with a length of $32 \mathrm{~mm}$, a $14 \mu \mathrm{m}$ diameter and density of $1.43 \mathrm{~g} / \mathrm{cm}^{3}$. The fibres were produced by means of an extrusion of plastic filaments from flakes of recycled polyethylene terephthalate.

Unreinforced mortar (matrix) and R-PET fibre reinforced composite specimens were prepared to study the influence of different R-PET reinforcement volume fractions $(1.0 \%$ and $2.0 \%$ ) on the compressive properties of the final material.

In all composites, the water/cementitious material ratio and superplasticizer content were dosed such that all mixtures would have similar fresh properties measured by the flow table test (between 160-190 mm). A slight adjustment in the superplasticizer content in each mixture was made to achieve consistent rheological properties for better fibre distribution and workability. The mixture proportions are given in Table 1.

To produce the mixtures, all dry raw materials were mixed for 3 minutes in a mechanical mixer with a 20-litre capacity. Water and superplasticizer were added to form the basic matrix and the mixture was stirred for another 8 minutes. Fibres were then dispersed carefully by hand into the mortar mixture and it was stirred for 5 minutes more. The specimens were cast in steel moulds, demoulded 24 hours after and, then, cured for 28 days in a curing chamber with $100 \%$ relative humidity and $21 \pm 1^{\circ} \mathrm{C}$ temperature. 
Table 1. Materials composition in the mixture.

\begin{tabular}{cccc}
\hline Ingredients & M01 & M02 & M03 \\
\hline Water / (cement + fly ash) & 0.36 & 0.36 & 0.36 \\
Cement $\left(\mathrm{Kg} / \mathrm{m}^{3}\right)$ & 505.00 & 505.00 & 505.00 \\
Fly ash $\left(\mathrm{Kg} / \mathrm{m}^{3}\right)$ & 605.00 & 605.00 & 605.00 \\
Sand $\left(\mathrm{Kg} / \mathrm{m}^{3}\right)$ & 404.00 & 404.00 & 404.00 \\
Water $\left(\mathrm{Kg} / \mathrm{m}^{3}\right)$ & 404.00 & 404.00 & 404.00 \\
Superplasticizer $\left(\mathrm{Kg} / \mathrm{m}^{3}\right)$ & 6.05 & 6.05 & 6.81 \\
Fibre $\left(\mathrm{Kg} / \mathrm{m}^{3}\right)$ & - & 14.33 & 28.66 \\
Fibre content $(\%)$ & - & 1.00 & 2.00 \\
\hline
\end{tabular}

\section{2.2 Testing procedure}

Dry density and total porosity of hardened composites were determined according to NBR 9778 [16], after 28 days of curing. A compressive test was performed at the age of 28 days in a Shimadzu universal testing machine (UH- FI-1000KN) controlled by computer under strain control and a loading rate of $0.2 \% \mathrm{FS} / \mathrm{min}$. The load and corresponding displacement were continuously recorded. Three 50 x $100 \mathrm{~mm}$ (diameter x height) cylindrical specimens were tested per composite mixture.

\section{RESULTS AND DISCUSSION}

\section{3.1 Porosity and dry density of composites}

The total porosity of the composites was found between $18.81 \%$ and $27.86 \%$, higher than the total porosity of the matrix (18.59\%). The volume of voids created by the addition of fibre is strongly linked to their characteristics (shape, thickness, length, and dosage added). The higher the amount of fibres, the higher will be the porosity induced.

Due to the low density of the R-PET fibre and the high pore volume induced by its addition, all the R-PET mixtures develop a lower dry density with respect to the matrix. Measured dry density of composite mixtures was in the range of 1440 to $1664 \mathrm{~kg} / \mathrm{m}^{3}$, while the matrix dry density was $1780 \mathrm{~kg} / \mathrm{m}^{3}$.

\section{3.1 Compressive behaviour}

Figure 1 shows the stress-strain curves obtained from the compressive tests. The results indicate that addition of PET fibres had little effect on the pre-cracking behaviour but had great effect on the post-peak behaviour of specimens. 

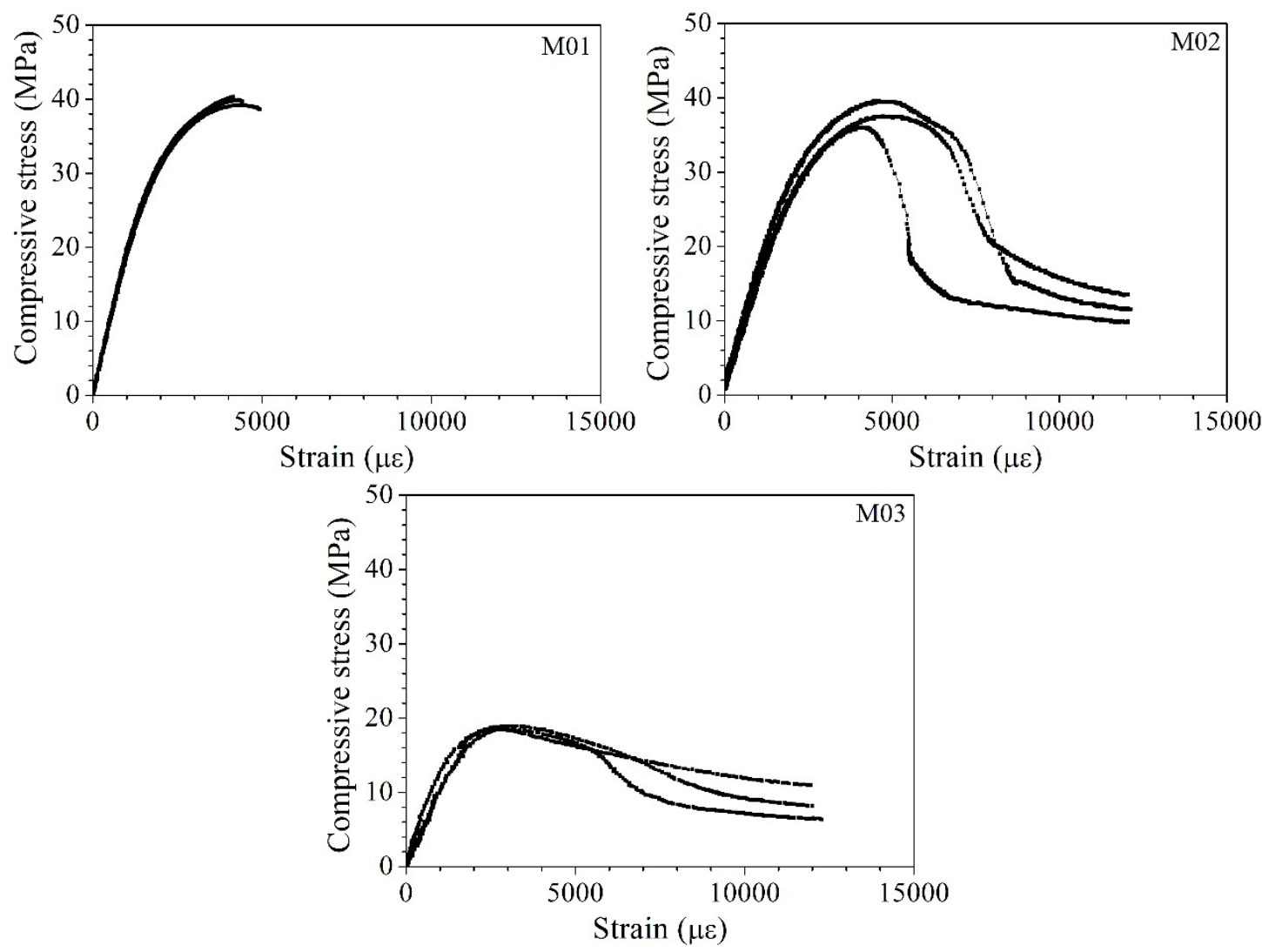

Figure 1. Compressive stress-strain curves of the matrix and fibre- reinforced composites.

For each specimen, the curve could be divided into four stages, i.e., linear elastic ascending stage, nonlinear ascending stage, cracking stage and residual softening stage [17]. After the applied loading reached approximately $48-52 \%$ of the compressive strength, the curves deviated from linear elastic behaviour and showed nonlinear behaviour up to the peak stress. This is attributed to the emergence and development of internal defects and micro cracks during the loading process. These two stages were similar for matrix and PET fibre reinforced composites. After the peak stress, the curves dropped with different slopes to a certain stress level. In the post-peak stage, the fibres in the matrix played an important role in bridging the cracks. For mixture with $1 \%$ fibre (M02), when the stress decreased to about $47 \%$ of the ultimate strength, an apparent inflection point appeared in the stress-strain curves. The curves after the inflection point were defined as residual softening stage, in which the stress decreased stably with the strain until final failure occurred. For the other mixture (M03, 2\%), the stress, in the post-peak stage, decreased stably with the strain until final failure occurred.

The mechanical properties of cement-based materials are important for structural analysis, and the main parameters include the peak stress (compressive strength), the strain corresponding to the peak load, the elastic modulus, and the toughness index. The compressive strength was calculated by dividing the peak load by the cross-section area of the specimen. The strain corresponding to the peak strength was obtained by dividing the displacement at the peak load by the gauge length of $50 \mathrm{~mm}$. The elastic modulus was calculated based on the method in NBR 8522 [18]. The compressive toughness was calculated as the ratio of area under the stress-strain curve up to strain of $120000 \mu \varepsilon$ and the equivalent area of the elastoplastic material with the same elastic modulus and compressive strength. The mean values and standard deviations (in parenthesis) are summarized in Table 2.

Table 2. Summary of physical and compressive tests of the mixtures at 28 days 


\begin{tabular}{ccccc}
\hline Mixture & $\begin{array}{c}\text { Elastic } \\
\text { modulus, GPa }\end{array}$ & $\begin{array}{c}\text { Compressive } \\
\text { strength, MPa }\end{array}$ & $\begin{array}{c}\text { Strain at peak } \\
\text { stress, } \mu \varepsilon\end{array}$ & Toughness \\
\hline M01 & $19.40(0.61)$ & $39.83(0.58)$ & $4227.88(74.33)$ & $0.30(0.04)$ \\
M02 & $14.43(1.11)$ & $37.73(1.76)$ & $4288.77(457.10)$ & $0.67(0.09)$ \\
M03 & $13.95(1.48)$ & $18.34(0.45)$ & $2969.41(92.33)$ & $0.78(0.04)$ \\
\hline
\end{tabular}

As seen from the results, the addition of R-PET had no beneficial effect on the compressive strength of the composite mixtures. A reduction of strength ranging from $5.3 \%$ to 54\% was observed for M02 and M03 mixtures when compared to the unreinforced mortar (M01). Similar effect was also observed in the elastic modulus. The elastic modulus of M02, and M03 were reduced by respectively $25.6 \%$ and $28.1 \%$. Results are coherent with ones from previous investigations $[13,15,19]$.

Figure 2 shows the relationship between the average porosity and compressive strength of the specimens. The increased porosity caused by fibre addition decreases the compressive strength and stiffness of the specimens (see Table 2).

The strain at peak stress indicates the deformability of the specimen at the ultimate strength. The results indicate that the average strain at peak load is between 2970 and $4290 \mu \varepsilon$ for specimens with different R-PET fibre content. Results demonstrate that addition of R-PET fibre reduced the strain at peak stress under compression. However, it is more evident when $2 \%$ of PET fibre was added.

Regarding post-peak behaviour, the results presented in Table 2 and Figure 1 indicate that the matrix without fibre is characterized by post-peak fragility; however, when R-PET fibre is added, the compressive toughness index of the composite was increased up to $217 \%$, indicating that the ductility was increased.

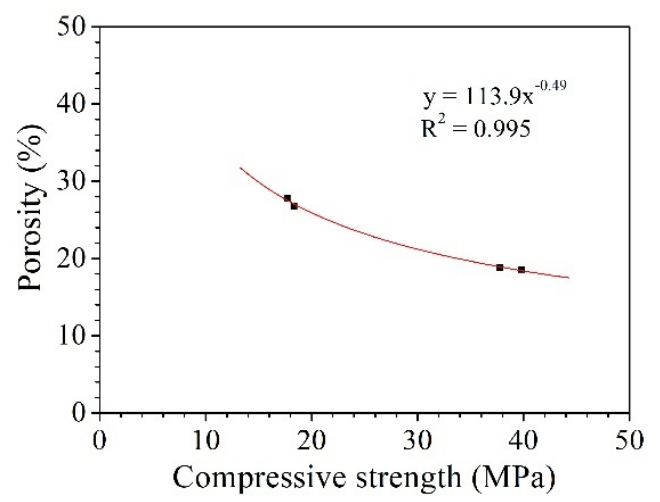

Figure 2. Relationship of porosity with the compressive strength.

\section{3.2 Analytical modelling of PET composites in compression}

There are many stress-strain relations for the modelling of concrete and fibre reinforced concrete in the literature. For the matrix without reinforcement, typical models present good agreement. Models by Desayi and Krishan [20] and Saenz [21] were used as shown in Fig. 3. Equations (1) and (2) show, respectively, the expressions for these models:

$$
\sigma=\frac{E \varepsilon}{1+\left(\varepsilon / \varepsilon_{0}\right)^{2}}
$$




$$
\sigma=\frac{E \varepsilon}{1+\left(E / E_{S}-2\right)\left(\varepsilon / \varepsilon_{0}\right)+\left(\varepsilon / \varepsilon_{0}\right)^{2}}
$$

where $\sigma$ and $\varepsilon$ are compressive stress and strain, $E$ is tangent Young's modulus, $E_{S}$ is secant Young's modulus (calculated at peak stress) and $\varepsilon_{0}$ is strain at peak stress. If the ratio $E / E_{S}$ is equal to 2, both models are identical, which is not the case as shown in Fig. 3.

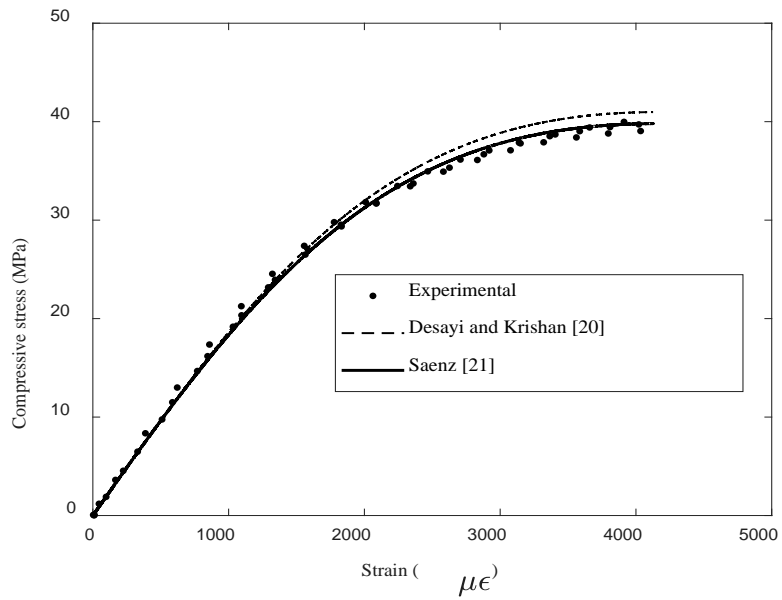

Figure 3. Stress-strain relation for the matrix

In the case of fibre-reinforced samples, $\mathrm{Xu}$ and Cai [22] proposed a model that presents 2 different expressions for the ascending $\left(0 \leq \varepsilon \leq \varepsilon_{0}\right)$ and descending $\left(\varepsilon>\varepsilon_{0}\right)$ branches, shown in Eq. (3). Based on the expressions proposed by Ezeldin and Balaguru [23], the descending branch was also modelled according to Eq. (4).

$$
\begin{aligned}
& \frac{\sigma}{f_{c}}=\frac{A\left(\varepsilon / \varepsilon_{0}\right)+B\left(\varepsilon / \varepsilon_{0}\right)^{2}}{1+C\left(\varepsilon / \varepsilon_{0}\right)+D\left(\varepsilon / \varepsilon_{0}\right)^{2}}, \quad\left(0 \leq \varepsilon \leq \varepsilon_{0}\right) \quad \frac{\sigma}{f_{c}}=\frac{\left(\varepsilon / \varepsilon_{0}\right)}{\left(\varepsilon / \varepsilon_{0}\right)+b_{0}\left(\varepsilon / \varepsilon_{0}-1\right)^{2}}, \quad\left(\varepsilon \geq \varepsilon_{0}\right) \\
& \frac{\sigma}{f_{c}}=\frac{\beta\left(\varepsilon / \varepsilon_{0}\right)}{\beta-1+\left(\varepsilon / \varepsilon_{0}\right)^{\beta}}, \quad\left(\varepsilon \geq \varepsilon_{0}\right)
\end{aligned}
$$

In Eqs. (3) and (4), $f_{c}$ is the peak stress and coefficients $A, B, C, D, b_{0}$ and $\beta$ are determined by curve fitting algorithm using MATLAB software [24]. Fig. 4 shows experimental and analytical curves in terms of nondimensionalized stress and strain and Table 3 shows the values obtained for each coefficient in the expressions. 

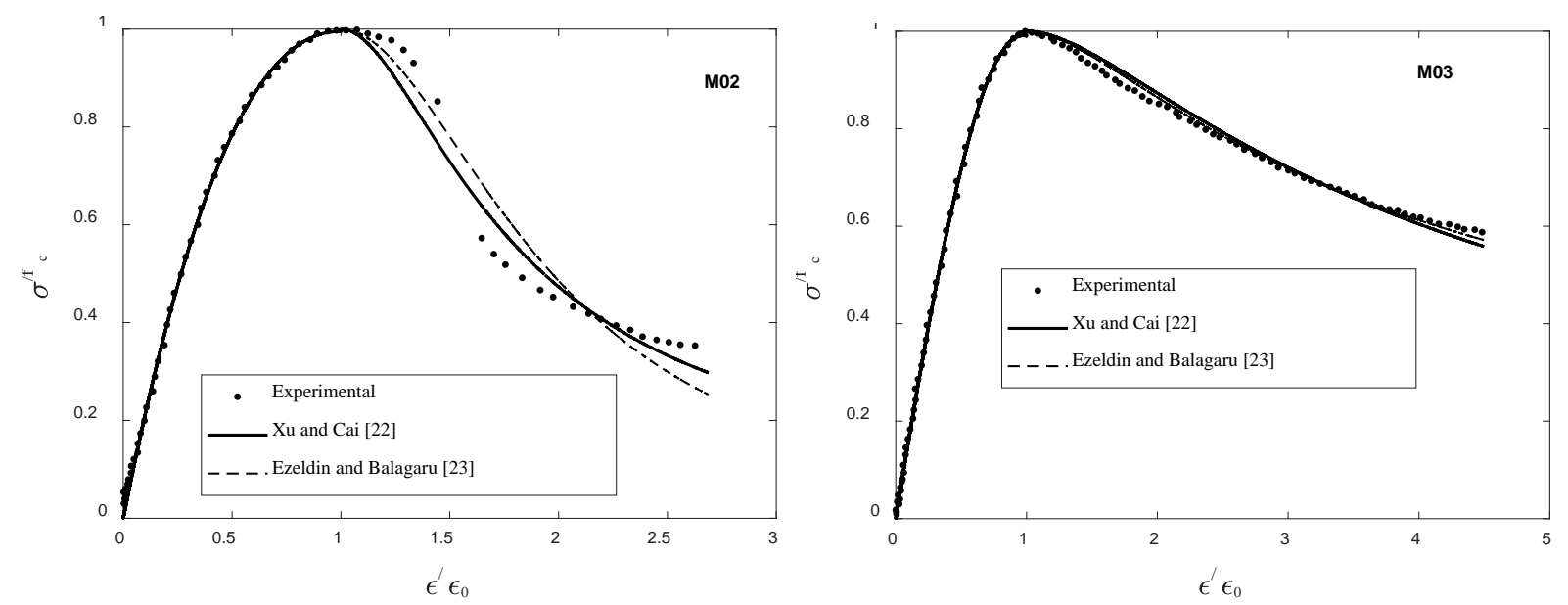

Figure 4. Experimental and analytical results

Table 3. Summary of coefficients obtained by curve fitting algorithm

\begin{tabular}{ccccccc}
\hline Mixture & $A$ & $B$ & $C$ & $D$ & $b_{0}$ & $\beta$ \\
\hline M02 & 2.252 & -0.8505 & 0.2489 & 0.1597 & 2.227 & 3.620 \\
M03 & 1.665 & -0.8797 & -0.3785 & 0.1716 & 0.2907 & 1.683 \\
\hline
\end{tabular}

\section{CONCLUSIONS}

Based on the results obtained in the present work it can be concluded that the use of recycled PET (R-PET) fibres as reinforcement of mortars is a promising technique for developing sustainable materials to be applied in the civil construction industry.

The main effects of the addition of R-PET fibres to mortars are:

- reduction of the compressive strength and elastic modulus of composite mixtures;

- reduction of the strain at peak stress under compression;

- $\quad$ increase in the compressive toughness index indicating increase in ductility.

A good agreement between experimental and analytical results was found. However, there is no physical meaning for the coefficients found by the curve fitting algorithm. Future works will focus on finding relationships between those coefficients and mechanical properties of specimens.

\section{ACKNOWLEDGEMENTS}

The authors acknowledge the Brazilian Agency FAPERJ for the financial support and M\&G Fibras Brazil LTDA for donation of the fibre.

\section{REFERENCES}

[1] ABIPET - Associação Brasileira da Indústria do PET. Décimo censo da reciclagem do PET no Brasil 2016.

In: http://www.abipet.org.br/index.html?method=mostrarDownloads\&categoria.id=3. Accessed on April 21, 2018.

[2] Choi Y.W., Moon D.J., Chung J.S. and Cho S.K., 'Effects of waste PET bottles aggregate on the properties of concrete', Cem Concr Res, 35 (4) (2005) 776-781.

[3] Frigione M., 'Recycling of PET bottles as fine aggregate in concrete', Waste Manage 30 (2010) 1101-1106.

[4] Azad A. M., 'Flexural behavior and analysis of reinforced concrete beams made of recycled PET waste concrete', Construction and Building Materials, 155 (2017) 593-604.

[5] Ochi T., Okubo S. and Fukui K., 'Development of recycled PET fiber and its application as concrete-reinforcing fiber’, Cem Concr Compos, 29 (2007) 448-455. 
[6] Kim J.J., Park C.G, Lee S.W., Lee S.W. and Won J.P., 'Effects of the geometry of recycled PET fiber reinforcement on shrinkage cracking of cement-based composites', Compos Part B: Eng 39 (2008) 442-450.

[7] Siddique R., Khatib J. and Kaur I., 'Use of recycled plastic in concrete: a review', Waste Manage 28 (2008) 1835-1852.

[8] Oliveira L.A.P. and Gomes J.P.C., 'Physical and mechanical behaviour of recycled PET fibre reinforced mortar', Constr Build Mater, 25 (2011) 1712-1717.

[9] Fraternali F., Farina I., Polzone C., Pagliuca E. and Feo L., 'On the use of R-PET strips for the reinforcement of cement mortars', Compos Part B: Eng, 46 (2013) 207-210.

[10] Magalhães M.S, Fernandes M.S.V., 'Bending Behaviour of Recycled PET Fiber Reinforced Cement-Based Composite’, Int J Eng and Tech 7 (2015) 282-285.

[11] Bentur A. and Mindess S., 'Fibre Reinforced Cementitious Composites, 2nd ed., Modern Concrete Technology, (CRC Press, 2006).

[12] Khalid, F.S., Irwan, J.M., Wan Ibrahim, M.H., Othman, N., Shahidan, S., 'Splitting tensile and pullout behavior of synthetic wastes as fiber-reinforced concrete', Construc and Build Mater, 171 (2018) 54-64.

[13] Kim S.B., Yi N.H, Kim H.Y., Kim J. and Song Y., 'Material and structural performance evaluation of recycled PET fiber reinforced concrete', Cem Concr Compos, 32 (2010) 232-240.

[14] Lu, C., Yu, J., Leung, C.K.Y., 'Tensile performance and impact resistance of Strain Hardening Cementitious Composites (SHCC) with recycled fibers', Construc and Build Mater 171, (2018) 566-576.

[15] Borg, R.P., Baldacchino, O., Ferrara, L., 'Early age performance and mechanical characteristics of recycled PET fibre reinforced concrete', Construc and Build Mater 108 (2016) 29-47.

[16] ABNT, NBR 9778: Argamassa e concreto endurecidos - Determinação da absorção de água por imersão - Índice de vazios e massa específica, (Brazil, 2005).

[17] Zhou J, Pan J, Leung C. K. Y., 'Mechanical Behavior of Fiber-Reinforced Engineered Cementitious Composites in Uniaxial Compression’, J of Mater Civil Eng. 27 (1) (2015) 1-10.

[18] ABNT, NBR 8522: Concreto - Determinação dos módulos estáticos de elasticidade e de deformação à compressão, (Brazil, 2017).

[19] Pelisser, F., Montedo, O., Gleize, P., Roman, H., 'Mechanical properties of recycled PET fibers in concrete', Mater. Res. 15 (2012), 679-686.

[20] Desayi, P. and Krishnan, S., 'Equation for the stress-strain curve of concrete', ACI J. 61 (1964) 345-350.

[21] Saenz, L.P., 'Discussion of "Equation for the stress-strain curve of concrete" by Desayi and Krishnan’, ACI. J. Proc. 61 (1964) 1229-1235.

[22] Xu, S. L., and Cai, X. R., 'Experimental study and theoretical models on compressive properties of ultrahigh toughness cementitious composites', J. Mater. Civ. Eng. 22 (10) (2010) 1067-1077.

[23] Ezeldin, S., Balaguru, N., 'Normal and high-strength fiber-reinforced concrete under compression', J Mater Civ Eng 4 (4) (1993) 415-429.

[24] [24] MathWorks, 'Curve Fitting Toolbox: for Use with MATLAB®: User's Guide', (MA, 2018). 